\title{
Idealized Compression Ratio for a Screw Briquetting Press
}

\author{
Peter Biath $^{1}$, Juraj Ondruška ${ }^{1}$ \\ ${ }^{1}$ Institute of Manufacturing Systems, Environmental Technology and Quality Management, STU Bratislava, \\ Námestie slobody 7, 81231 Bratislava
}

Correspondence to: peter.biath@stuba.sk

\begin{abstract}
This paper deals with issues in determining the ideal compression ratio for a screw briquetting press. First, the principles of operation and a basic description of the main parts of a screw briquetting press are introduced. The next section describes the pressing space by means of $3 \mathrm{D}$ software. The pressing space was created using a Boolean subtract function. The final section of the paper measures the partial volumes of the pressing chamber in CATIA V5 by function of measuring. The measured values are substituted into the formula for the compression ratio, and the resulting evaluations are presented in the diagram in the conclusion of this paper.
\end{abstract}

Keywords: screw briquetting press; compression ratio; calculation of compression ratio.

\section{Introduction}

Briquetting is the most widely-used waste compaction technology. Briquettes made by screw briquetting presses are of the highest quality. In this paper, we will deal with the screw briquetting presses produced within the project "Developing progressive technology of biomass compaction, production of prototypes and highly productive tools" co-financed by the European Structural Funds. The research is complex, ranging from a study of elementary biomass particles to the production of a new design and structure for briquetting machines and briquetting machine tools. The purpose of the study is to design and verify a prototype for a new progressive briquetting machine design, and to develop highly productive tooling.

The paper attempts to clarify the procedure for calculating the idealized compacting ratio during compaction in our screw briquetting press. The results will clarify how the material changes in volume during compaction (although only idealized), and will be of great benefit to further research and development of screw presses.

\section{Description of a screw briquetting press}

In developing the design of a new press, we apply research results for the parameters that influence the biomass compaction process. When managing the technology and constructing the pressing parameters, it is important to achieve high-quality production in a variety of factors. The following experiments and the optimization to be implemented on the machine will reflect real compaction technology in practice. The research area focuses on the principle of screw presses due to the achievement of the highest with a view to achieving the highest quality production using this principle. However, one big disadvantage of this type of machine is its short bearing and worm tool life, due to the high axial pressures.

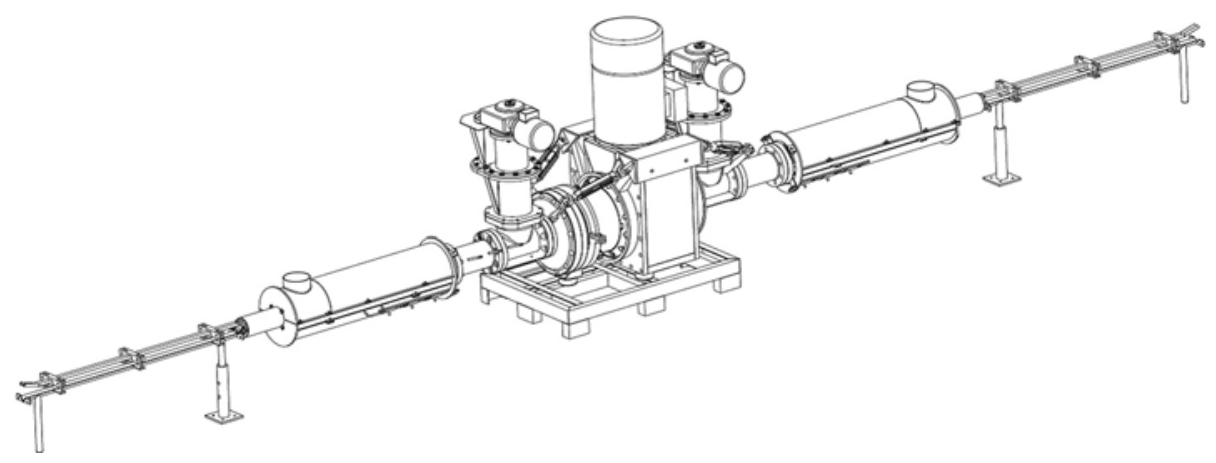

Figure 1: Screw briquetting press 


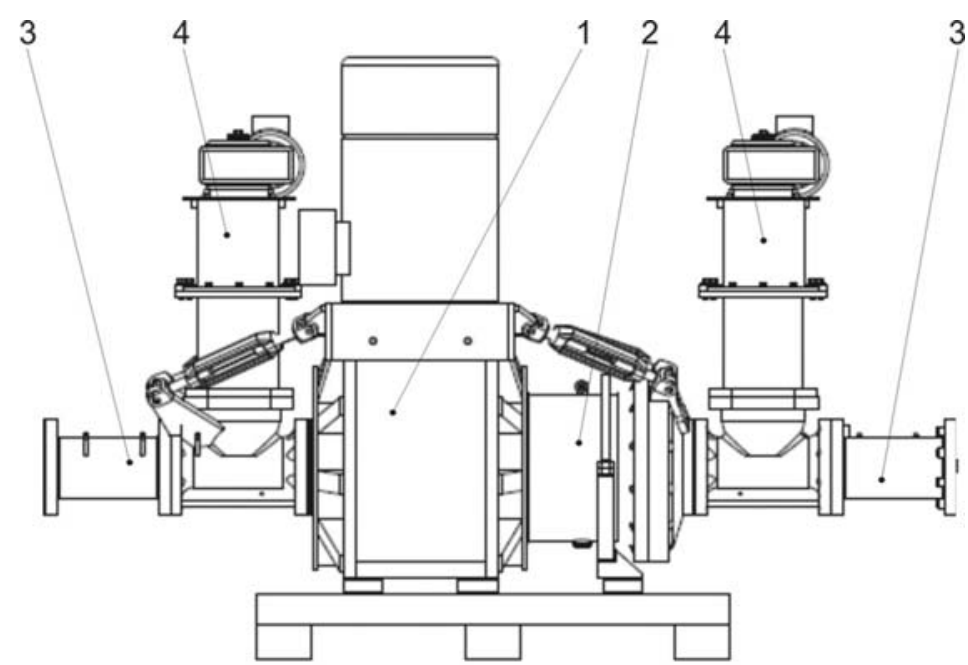

Figure 2: Basic parts of the new screw press $(1$ - drive, 2 - storage node for screw and spindle, 3 - pressing chamber, 4 - feeding system)

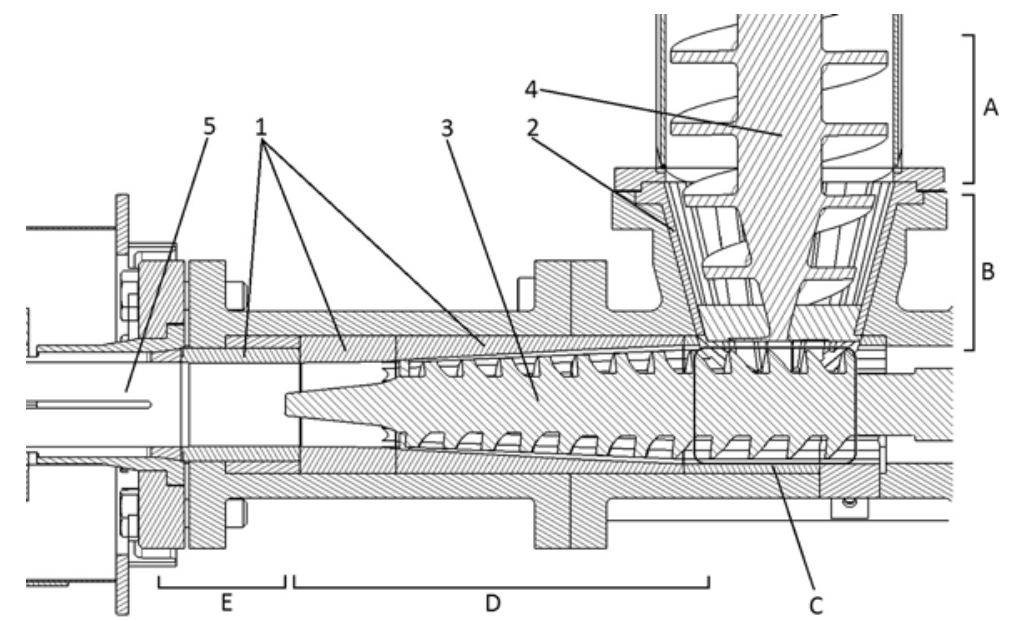

Figure 3: Pressing chamber (1, 2 - nozzles; 3 - pressing screw, 4 - feeding screw, 5 - collet, A, B, C, D, E - location of compaction)

The basic structure of a briquetting press is shown in Figure 2. The design of the machine is doublechambered to eliminate sharp rises in axial force. The primary parts of the machine are its main drive, the storage node for screw and spindle, the pressing chambers, the cooling channels and the two feeding systems. The core of the machine is held on frames which are similar in dimensions to euro pallets for better manipulation during transportation. It is not necessary to anchor the machine during operation, because the frame of the machine does not transmit any workloads.

The machine is developed to be modular, making it easy to change it from a double-chamber version to a single-chamber version simply by removing one part of the machine - from the drive side, without any other modifications. The single-chamber structure is very helpful, especially in experiments and measurements, because we can measure a wide range of operating parameters, including the entire workload, during operation.

\section{Pressing space}

The pressing space in compaction machines is created from moving and stationary parts. In our case it comprises the pressing screws (positions 3, 4; Figure 3) and the nozzles (positions 1, 2; Figure 3). The pressing space in our equipment is quite complicated, because there are two screws (for pressing and for feeding) in each side. The first screw is for feeding (4). It transports material into the throat of the pressing chamber and overwhelms the second "pressing" screw (3). There is compaction of the material even in the feeding screw, so we will include it in the pressing space in order to determine the total pressing space of the machine. 
The compaction process starts at position A, where the feeding screw moves the material from the hopper to its grooves. At this moment, the bulk material has the same density as the material in the hopper. However, when the material begins to enter the conical part of the feeding screw (B) its volume decreases and its density increases. The compacted material at the end of the feeding screw moves to the overloaded space of the pressing screw (C) without changing density, but only in ideal conditions. In this space we will consider the same density, because the first part of the pressing screw is feeding (the screw and the nozzle are cylindrical in shape without any change in shape or into the conical parts). In the subsequent space, the material is again compacted (D) by the taper of the nozzles and the change in the pressing screw geometry. The compacted material then moves to the last part of the pressing chamber (E). Here the pressing pressure is generated only by back-pressure, which is caused by the change in the collet (5) section. However, in this paper we will pay attention to creating the compression ratio by screw compaction only. Thus the pressing space that we are studying ends up at the last thread of the pressing screw. However, we should not forget that the output of this experiment will be idealized, meaning that, if we neglect the resistance and friction within the pressed material and the friction of the compacted material in the pressing chamber, the following will apply: if the screw turns one revolution then the material will move by the value of one thread pitch.

We used CATIA V5 3D software to create the pressing space. We identified the components which create the pressing space (the hopper, the feed screw (4), the feed screw nozzle (1), the pressing screw (3), and the pressing screw nozzles $(1,2,3)$,$) .$ In assembling the model, we created components (tubes) that create the theoretical fill of the pressing space in both screws. The tube dimensions must be designed in such a way that the smallest diameter of the tube must be smaller than the smallest diameter of the screws (screw grooves), and the largest diameter of the tube must be larger than the largest diameter of the individual nozzles (longitudinal grooves in the nozzles). The dimensions of the tubes were designed with respect to the Boolean subtract operation, where we need to intersect the bodies and then subtract the intersections from one another. Figure 4 shows the pressing space that is created, with and without screws. After this, the pressing space will be divided into smaller parts, and then we will measure its volumes.

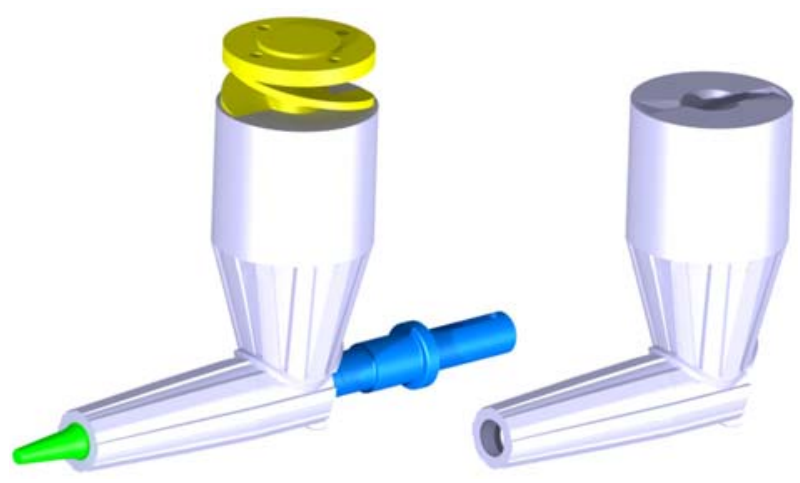

Figure 4: 3D model of the pressing space

\section{Measuring volume of the parts in the pressing space}

To find the compression ratio, it is necessary to divide the model of the pressing space transversely into smaller parts. The resulting smaller volume parts will be measured. Transversely dividing the model results in one quarter of the screw pitch. The feed screw is double-grooved with a pitch of $120 \mathrm{~mm}$, and the pressing screw is single-grooved with a pitch of $31.8 \mathrm{~mm}$. The step in dividing the feed screw is $30 \mathrm{~mm}$, and for the pressing screw the step is $7.95 \mathrm{~mm}$. We do not list the individual measured values in the paper but only mention them in the diagram in the next section.

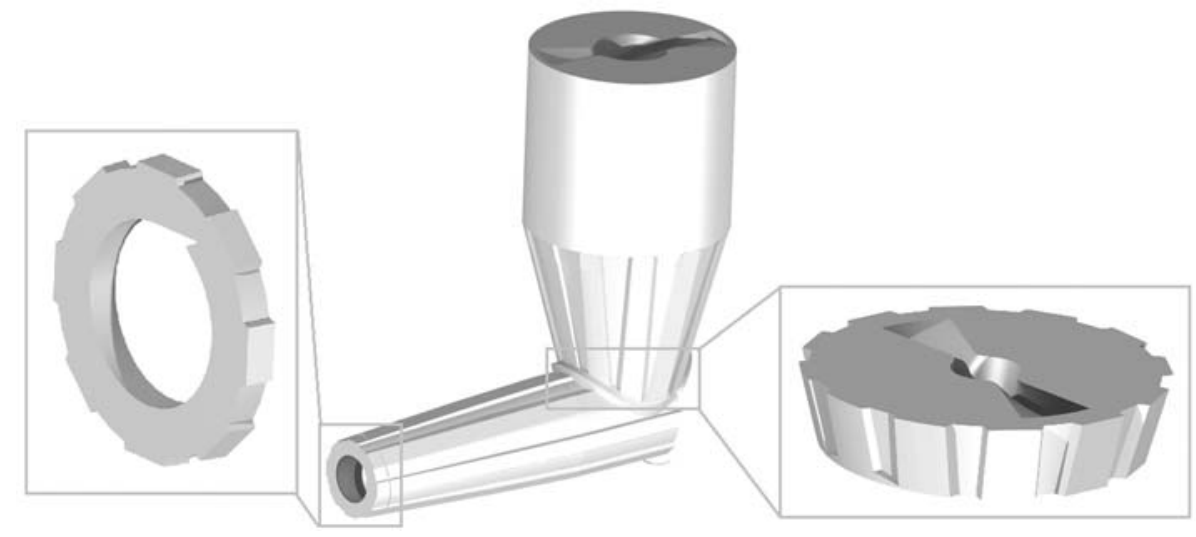

Figure 5: 3D model of the pressing space — volume parts 


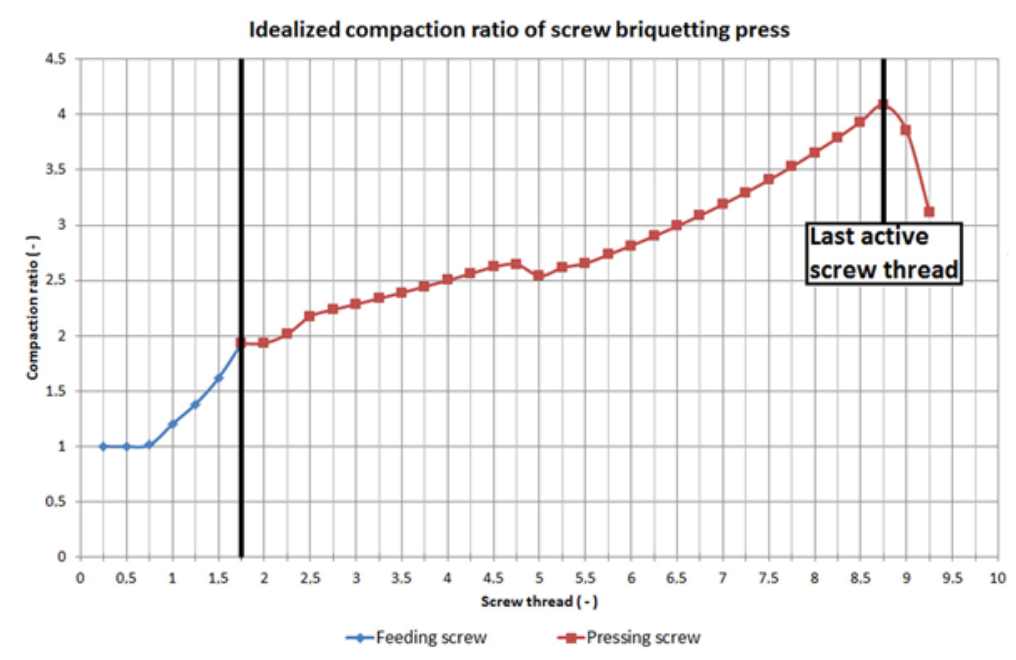

Figure 6: Diagram of the idealized compression ratio of a screw press

\section{Measurement evaluation}

The compression ratio is the ratio between the bulk material volume before compaction and the volume of the compacted material after or during compacting. The value of the compression ratio indicates how much the input volume decreases during the compacting process. The feeder compression ratio is the ratio of the given hopper material volume to the particular measured volumes in other feeding screw sections.

$$
z p_{P i}=\frac{V_{D P \max }}{V_{D P i}},
$$

where $\left(z p_{P i}\right)$ is the compression ratio in any given screw section of the feeder, $\left(V_{D P \max }\right)$ is the maximum input volume of pressed material in the feeder, $\left(V_{D P i}\right)$ is the volume of the measured part in any given screw section of the feeder.

It is necessary to determine the compression ratio separately in mechanically separate phases of the process. The resultant compression ratio in the pressing space of the pressing chamber is the product of the compression ratio in the feeder and the partial compression ratios of the pressing screw.

$$
z p_{L i}=\frac{V_{D L \max }}{V_{D L i}} \cdot z p_{P \max },
$$

where $\left(z p_{L i}\right)$ is the compression ratio in a given screw section of the pressing space, $\left(V_{D L} \max \right)$ is the maximum input volume of pressed material in the pressing space, $\left(V_{D L i}\right)$ is the volume of the measured part in a given screw section of the pressing space, and $\left(z p_{P \max }\right)$ is the maximum compression ratio in the feeder.

By substituting the measured values into the formula we find the character of the compression ratio, which is shown in the diagram below. Figure 6 is divided into two parts: the first presents the compression ratio in the feeding space, and the second describes the compression ratio in the pressing space. The undulation of the character of the compression ratio is influenced by the change in the geometry of the screws and nozzles.

\section{Conclusion}

The values and the character of compression ratio in this paper are idealized. In the real process we cannot consider it as completely relevant, for example, to determine real compression by a direct calculation, because multi-axial compaction processes are very complex and difficult to describe theoretically. The behavior of the material during compaction is influenced by technological and design parameters. The results of this experiment will be compared with real experiments and measurements. The results that are obtained will be used to create a basic idea about the processes inside the chambers during compaction on this screw press. Further research should determine the real compression ratio in this machine.

\section{Acknowledgement}

This paper reports on work done in the project "Developing of progressive technology of biomass compaction and production of prototypes and highly productive tools" (ITMS code of the project: 26240220017), supported by the Research and Development Operating Programme funded by the European Regional Development Fund.

\section{References}

[1] Biath, P., Ondruška, J., Šooš, L'.: Theoretical calculation of PLG 2010 press compression ratio. Briquetting and pelleting 2012. Bratislava: STU, 2012, s. 117-123. ISBN 978-80-227-3641-1.

[2] Matúš, M., Križan, P.: Development of a progressive machine design for biomass briquetting. Briquetting and pelleting 2012. Bratislava: STU, 2012, s. 197-202. ISBN 978-80-227-3641-1. 